\title{
The Effects of Economic Freedom Components on Economic Growth: An Analysis with A Threshold Model
}

\author{
Hatem DERBEL \\ Researcher at Economix (University of West Paris Nanterre La Défense) \\ and \\ at URDEE 99/UR/06-10 (FSEG University of Sfax ) \\ University of West Paris Nanterre La Defense \\ 200, avenue de la République U.F.R SEGMI bât.G, bureau 610 E 92001 Nanterre Cedex \\ Tél: 33-1-40-97-77-92, Fax: 33-1-4097-7784Ｅ-mail: derbelhatem@yahoo.fr
}

\section{Rami ABDELKAFI}

Assitant Professor at the FSEG University of Sfax and member of URDEE 99/UR/06-10

Faculty of Economics and Management of Sfax

Route de l'Aéroport km 4 - 3018 Sfax

Tél: 216- 74-27-97-10 Fax: 216- 7427-9139Ｅ-mail: abdelkafirami@yahoo.fr

\section{Ali CHKIR}

Professor at the FSEG University of Sfax and Director of URDEE 99/UR/06-10

Faculty of Economics and Management of Sfax

Route de l'Aéroport km 4 - 3018 Sfax

Tél: 216- 74-27-97-10Ｆax: 216- 7427-9139Ｅ-mail: Ali.chkir@fsegs.rnu.tn

Received: March 18, $2011 \quad$ Accepted: April 7, $2011 \quad$ doi:10.5539/jpl.v4n2p49

\begin{abstract}
Several studies show a positive and significant link between economic freedom and economic growth. Based on this result many economists recommend an abrupt and total disengagement of the State from the economic activity. One of our principal results is that the reduction of the size of the government is not effective in countries having an initial GDP per capita and an enrollment rate in 1990 higher than the thresholds values. This enables us to put into perspective the need for a reduction of the size of the government and to insist on the effectiveness of economic policies in developing countries.
\end{abstract}

Keywords: Size of the government, Economic freedom, Economic growth, Threshold model

JEL classification: C13, C21, H10, H11, H50, O10

\section{Introduction}

In spite of the abundance of theoretical and empirical works, economic theory still until now unable to give a complete and exact specification of all variables having a significant impact on economic growth. Indeed, several models seem to be logical but give very different results that make very difficult to decide what lessons we can draw for economic policies. But, although different in their conclusions and in the importance that each one gives to growth factors, these works agree on the fact that economic environment can determine the effectiveness of the various factors and their influence on economic growth.

Recently, the concept of economic freedom was advanced by several authors as a necessary condition and an effective mean to promote economic growth. Boockmann and Dreher (2001), for example, note that liberalization and privatization are the main objectives of the programs and policies of the IMF and the World Bank. So, based on liberal ideas, the economic freedom tries to reduce to the minimum the role assigned to the government and to 
amplify that of the market and the private sector. On the basis of these ideas, some studies try to empirically confirm the positive correlation between economic freedom and growth. So using an index of economic freedom (hereafter $E F I$ ), these studies try to show a positive relationship between this index and some development measures of which the most significant still the GDP per capita. In the context of developing countries, the investigation into the causes of failure, often evoked, of economic policies concern two types of different but dependent questions. The first one is related to the theoretical justification of these policies and the active role of governments in the economy. The second is related to the effectiveness of any intervention, even socially justified, of the government and it is generally considered that this effectiveness depends on political, institutional, geographical and economic factors.

Based on some empirical results showing, at the same time, the effectiveness of economic freedom and the inefficiency of public interventions in some countries, several economists present the total liberalization of the economy as a priority and a standard action that all countries must apply independently of their context and without any conditions.

The aim of this paper is double. First, it is to show that the use of an aggregate index can mask the complexity of the link between economic freedom and growth as well as the importance of its various components. Second, it is to show that the link between economic freedom and growth could depend on the development level of countries. The remainder of the paper is organized as follows: section 2 discusses the method used in our estimations and justifies the choice of the explanatory variables. Section 3 tries to give a brief idea about the concept of economic freedom and its various components. Section 4 is devoted to the empirical study in which we try to analyze the link between economic freedom and growth. The conclusion is presented in section 5 .

\section{Economic growth factors: multiple explanations but weak relations}

Economic literature remains until now unable to provide an exact specification of the link between economic growth and its determinants. The multiplicity of these determinants has amplified the difficulties to analyze their nature and their importance in the development process. Thus two problems have taken more importance in recent studies on economic growth. The first one is a continuity of old efforts trying to widen the field of analysis and to integrate more explanatory factors of economic growth. The second, on the other hand, tries to reduce this field by insisting on the robustness of links that some empirical works propose. In an article, considered as a reference for the majority of recent works on economic growth, Levine and Renelt (1992) deal with the problem of the multitude of specifications used to study the effects on economic growth. These authors show that the majority of these specifications are not robust and that the relations demonstrated between economic growth and some other variables must be putted into perspectives (Note 1). Temple (2000) notes that the estimated parameters are likely to be much correlated with studied variables so the specificities of countries and their development levels can influence the importance of integrated variables and by there the results obtained. But, a more optimistic view point can be found at Sala-i-Martin (1997) who considers that the impact of many variables on economic growth is certain. Thus, it is not the pessimistic vision drawing aside a great number of variables which must characterize the studies on economic growth (Note 2). Generally, even the strictest view points agree on the need for integrating some variables having an unquestionable impact on economic growth. Thus, initial GDP, investment and several measurements of human capital are regarded as "standard variables" and always correlated with economic growth.

Recently, economists are more interested in integrating institutional factors in growth regressions. Hall and Jones (1996), for example, insist on the role of social infrastructure, which includes institutions and government policies, in economic growth. In particular, they show that the difference in the output by worker between countries is explained only partially by the difference in their physical capitals and their education levels. The same authors show that the difference in the stock of physical capital and in productivity can be explained by institutional factors and many other variables relating to economic policies. In this new wave of empirical works, the integration of an index of economic freedom in growth regressions comes to enrich the debate relating to the respective roles of the State and the market in the development process. Motivated, at the same time, by liberal ideas and by the significant progress realized in calculating some indexes of economic freedom, several studies try to advance the benefits of economic liberalism.

\section{The concept of economic freedom}

The index of economic freedom measures the degree according to which institutions and various policies of a country encourage freedom. It is based on the personal choices, the freedom to exchange, the freedom of competition and the safety of private properties. According to the Fraser Institute report, the African countries, those of Latin America and the former communist countries are less classified in terms of economic freedom. The same report notes that countries with a high score in economic freedom rating have relatively higher growth rates and better social indicators such as life expectancy. Thus, it is considered that market creates an environment in which it 
would be very difficult for authorities to exert pressures on people. On the concept of economic freedom, the report notes that the key ingredients of economic freedom are personal choice, voluntary exchange coordinated by markets, freedom to enter and compete in markets, and protection of persons and their property from aggression by others. So this concept assigns to the government the role of establishing a legal structure which ensures the correct operation of free market. However, this government must be disengaged of any activity which is likely to compete with the private sector and the correct operation of competition. Thus, economic freedom will be reduced if public expenditures and regulation policies replace some private activities. Entirely, the construction of the economic freedom index is based on 38 components and sub-components which relate to five different fields.

The first one is relating to the size of the government in the economy. So it is considered that public expenditures as well as subsidies and transfers are variables which limit economic freedom. In the same way, it is a question of seeing up to what point the production is realized by private enterprises rather than by public ones. The second is relating to legal structure and safety of property rights. Generally, it consists to see up to what point laws in force in the economy respect freedom to exchange and if private agents have confidence in these laws so they protect their private interests. The third field concerns inflation stability and consistency of monetary policies. In particular, it consists in studying the inflation volatility and the possibilities offered to the private sector to have access to foreign currencies which are safer and more stable than its national currency. The fourth field is relating to free trade and the opening of the economy to outside. It is about the ability of the private agents to exchange with foreigners. The last field is interested in regulations which can exist in the credit market, the labor market and the goods market.

The economic freedom index has made it possible to several studies to test the link which can exist between economic freedom and some economic indicators of which the most popular remains always income par capita. For example, some studies are based on heterogeneous samples including developed and developing countries arrive at conclusions showing a positive correlation between economic freedom and growth (Shaefer, 2003; Gwartney an al., 2005; Gwartney and al., 2004; Cole, 2003; Esposto and al., 1999). Some other studies (Soysa and Neumayer, 2004; Stroup, 2003) go further and show a positive effect of economic freedom on environmental quality.

Our empirical work is motivated by the conviction that economic freedom effects on growth can be conditioned by differences in development levels. It is very clear that the construction of the economic freedom index integrates some variables having effects which remain until now a subject of debate in economic literature. In fact, if economists are almost unanimous on the importance of the respect of property rights and personal freedom, they remain divided on the role assigned to the public sector and the effects of free trade on economic development. Thus we try in our empirical part to decompose the effect of economic freedom on growth and to highlight the differences which should exist between countries regarding to their development levels.

\section{Empirical analysis of the economic freedom-growth link}

\subsection{The estimated model}

Our approach in this part is progressive and consists in two different stages. In the first, we introduce the aggregate $E F I$ in a growth regression explaining the growth rate of GDP per capita (noted $G D P G$ ) according to other variables. In the second, we try to decompose the EFI by replacing it by its various components in the same regression. Thus, we introduce the variable expressing the size of the government (noted $S G$ ), the variable indicating the legal system quality (noted $L S$ ), the variable expressing free trade (noted $F T$ ), the variable expressing the inflation volatility and the consistency of monetary policies (noted $S M$ ) and the variable indicating the regulation on the various markets (noted REG).

According to liberal ideas, the coefficient of the EFI must be positive and significant implying a positive effect of economic freedom on growth. In the same way, the coefficients related to the various components of the index should be positive. Indeed, the higher is the score of a country in each one of these variables, the more liberal is this country. For example, a higher score of a country in the variable $S G$ indicates a smaller weight of the government in the economy.

The relatively big size of our sample enables us to integrate a high number of variables without reducing in a considerable way the degree of freedom. However, integrating a bigger number of variables having a link with economic growth as well as the study of the robustness of this link exceeds the contours of our work and is likely to mask the importance of the various economic freedom components. For this reason, we integrate only variables of which effects on growth are confirmed and regarded as robust by the majority of former studies (Levine and Renelt, 1992; Sala-i-Martin, 1997; Temple, 2000). Therefore, in addition to variables relating to economic freedom, we introduce the logarithm of initial GDP per capita (noted $L G D P_{t 0}$ ), the enrollment ratio in secondary school (noted $S C O$ ) (Note 3) and the share of investment in GDP (noted $I N V$ ). Entirely, we have the following regressions: 


$$
\begin{aligned}
& G D P G_{i}=c_{1}+\alpha_{1} L G D P_{i t_{0}}+\alpha_{2} S C O_{i}+\alpha_{3} I N V_{i}+\alpha_{4} E F I_{i}+\varepsilon_{i} \\
& G D P G_{i}=c_{2}+\beta_{1} L G D P_{i t_{0}}+\beta_{2} S C O_{i}+\beta_{3} I N V_{i}+\beta_{4} S G_{i}+\beta_{5} L S_{i}+\beta_{6} S M_{i}+\beta_{7} F T_{i}+\beta_{8} R E G_{i}+\delta_{i}
\end{aligned}
$$

\subsection{Estimation with the aggregate index of economic freedom}

Our study covers the period ranging between 1972 and 2003. Thus GDPG represents the average rate of GDP per capita over this period (Note 4). The variable $I N V$ is the average over the same period of investment share in GDP. The data of these two variables are extracted from the Penn World Tables 6 (Note 5) For the variable SCO, lack of data over the total period and for all countries of the sample led us to use the average over the period ranging between 1990 and 1996. Data for this variable is obtained from the WDI 2003 of the World Bank. Lastly, all data relating to economic freedom are extracted from the Fraser Institute database (Note 6) For these variables, data are available in intervals of five years over the period ranging between 1970 and 2000. Moreover, data are available for all variables and for all countries only since 2000. However, we use the average of the variables over the period 1985-2000. This choice enables us to avoid the return effect which could exist between economic freedom and growth (Heckelman and Stroup, 2000; Chong and Calderón, 2000; Dawson, 2003). Then by this way, we can take account of the delay effect in the link between the two variables (Carlsson and Lundström, 2002).

At the beginning, our sample comprised 104 countries at various development levels (Note 7). Thus heterogeneity is likely to influence the quality of our results because of the existence of some outliers that deviate from the general tendency of the sample. These outliers can have a big weight in such a way that they strongly influence the results. Therefore, to be robust, these results shouldn't be extracted from a small number of observations characterized by a relation that is different from that expressed by the estimated model (Temple, 1999; 2000). Outliers occur frequently because of the measurement errors, owing to the fact that some observations are extracted from a sub-sample characterized by a relation that differs from the general model, or because of the presence of some exceptional events (Bengtsson and al., 2005). In the presence of such outliers, the use of the Ordinary Least Squares (OLS) method is inadequate. In this case, the use of the LTS (Least Trimmed Squares) method is necessary to detect the presence of atypical values (Note 8).

By applying the LTS method in our regressions they showed the presence of three outliers which are China, the Democratic Republic of Congo and Zambia (Note 9) This led us to use the FWLS (Final Weighed Least Squares) which consists in assigning the value 0 to outliers and the value 1 to the other observations. Table 1 gives a comparison of the results obtained with the OLS method and those obtained with the FWLS method. This table shows that the results obtained with the two methods are very close. In both cases, all the coefficients are significant and have the awaited signs. The $E F I$ is characterized by a positive and statistically significant coefficient. Therefore, like the majority of empirical works, our results show that the use of an aggregate index of economic freedom results in a positive effect of the latter on economic growth.

\subsection{A decomposition of the EFI}

The use of an aggregate index of economic freedom can mask the true characteristics of the link that can exist between freedom and growth (Carlsson and Lundström, 2002; Bengtsson and al., 2005; Heckelman and Stroup, 2000). First, it is completely reasonable to think that some components of the index can have a positive effect on economic growth, while other components exert a rather negative effect. Second, the importance of these effects can be different between countries.

Our objective in this part is to analyze the effect of the various components of the $E F I$ on economic growth. Thus we try to test the relation (2) described previously. The countries which are outliers were withdrawn from the sample, so the number of countries is reduced to 101 only. Then, we applied the same step as previously to detect outliers in this model. The application of the LTS method showed that Botswana is an outlier (Note 10). Thus, on the whole, the number of countries included in the estimation of relation (2) is equal to 100 . The results of the estimation are given in table 2 .

According to the results presented in table 2, the detection of outliers is very important. Indeed, the coefficient of $S G$, insignificant in the sample including Botswana, becomes significant and positive in the sample without this country. This result means that reducing the size of the government in the economy would result in a positive effect on growth. Values of the variance inflation show the absence of multicollinearity problems in our estimations.

Up to now, our results agree with those of liberal economists considering the reduction of the size of the government in the economy as a necessary and efficient mean to stimulate economic activity. But, although our study takes account of the existence of outliers, it is important to note that conclusions, up to now drawn concerning the importance of economic freedom and the role of the government, are based on a strong assumption considering that the estimated model is linear on the entire sample and that all countries obey to the same specification. Such an 
assumption can be checked within a Solow growth model. On the other hand, according to new economic growth theories, it is essential to test the validity of this assumption and to see whether the relation between variables can change according to the characteristics of countries (Durlauf and Johnson, 1995).

\subsection{The detection of threshold variables}

A routine practice in econometric analysis consists in testing the stability of estimated parameters on the whole of the sample or the period. However, in these practices, it is necessary to choose the threshold variable a priori. By using the GDP and the literacy rate to differentiate countries, Durlauf and Johnson, 1995 reject the assumption of a homogenous and linear specification on the entire sample. Based on this study, Hansen, 2000 proposes a test that makes it possible to determine the variable of transition between various regimes endogenously. The test can be used both in the case of time series and cross-section data (Note 11). Moreover, the variable for which one can test the presence of a threshold can belong to explanatory variables of the regression or to be an external variable to this regression.

The model proposed by Hansen (2000) can be presented as follows:

$$
\begin{array}{ll}
Y_{i}=\theta_{1}^{\prime} x_{i}+e_{i} & q_{i} \leq \gamma \\
Y_{i}=\theta_{2}^{\prime} x_{i}+e_{i} & q_{i}>\gamma
\end{array}
$$

Thus it is a question of testing the assumption $H_{0}: \theta_{1}=\theta_{2}$ where $q_{i}$ is the threshold variable that divides the sample into two groups; $Y_{i}$ is the dependent variable; $x_{i}$ is the independent variable; $e_{i}$ is the error term and $\gamma$ is the threshold value. Assume that $I_{i}(\gamma)$ is a dummy variable with $I_{i}(\gamma)=\left\{q_{i} \leq \gamma\right\}$ and that $\{$.$\} is an indicator$ function. Thus we have $I=1$ if $q_{i} \leq \gamma$ and $I=0$ otherwise. If we pose $x_{i}(\gamma)=x_{i} I_{i}(\gamma)$, relations (i) and (ii) can be written as follows:

$$
Y_{i}=\theta^{\prime} x_{i}+\delta_{n}^{\prime} x_{i}(\gamma)+e_{i} \text { where } \theta=\theta_{2} \quad \text { and } \delta_{n}=\theta_{1}
$$

Like Durlauf and Johnson, 1995 we focuse our attention on the initial GDP per capita and the initial schooling rate as possible threshold variables. Thus by using the Hansen test, we test the presence of a threshold on initial GDP per capita $\left(G D P_{72}\right)$ and initial enrollment rate. However, as noted previously, the enrollment rate in 1972 is not available for all countries. For this reason, we use the value of 1990 for this variable (noted $S_{C O} O_{90}$ ).

Table 3 contains the results of the test using 1000 replications. This table shows that the null assumption of stability of coefficients on the entire sample is rejected for the two variables $G D P_{72}$ and $S C O_{90}$ characterized by very small p-values. So, each one of these two variables divides our sample in two different groups according to the relationship between variables. For the variable $G D P_{72}$, the optimal threshold value is equal to 2080.46 implying that this variable divides our sample in two groups of countries according to their initial GDP per capita. The first group (noted G1) comprises 66 countries having an initial GDP lower than 2080.46 whereas the second (noted G2) comprises the 34 remaining countries. For the variable $S_{C O}$, the optimal threshold value is equal to 81.456 what divides our sample in two groups according to this variable. A group (noted G3) comprising 73 countries having an enrollment rate in 1990 lower than 81.456 and another group (noted G4) comprising the remaining countries (Note 12).

Table 4 gives the results of the estimations of relation (2) for the two groups G1 and G2. These results show that our sample is characterized by two different regimes. In G1, comprising countries with an initial GDP per capita lower than 2080.46; we can see that $L G D P_{72}, I N V$ and $S C O$ are characterized by significant coefficients and with the awaited signs. In the group G2 of countries having an initial GDP higher than 2080.46, only the variable $L G D P_{72}$ is characterized by a significant coefficient and with the awaited sign. The variable $S C O$ has a negative and significant coefficient. This result can be explained by the heterogeneity of this group and by the presence of some countries which have a high GDP per capita and a small enrollment rate like Kuwait and UEA, or by the fact that the majority of countries in this group have reached the maximum level of enrollment.

About the components of economic freedom, we can notice that they do not exert the same effect in the two groups of countries. In fact, we can see that in G1 only the variables $S G, L S$ and $S M$ are significant. So a reduction in the size of the government, an improvement in the quality of the legal system and a consistent monetary policy exert a positive effect on economic growth in this group. However, for G2, significant variables are $S G, F T$ and $R E G$. But what is interesting is that the sign of the variable $S G$ is changed and become negative. This result means that for these countries a reduction in the size of the government results in a negative effect on economic growth. 
Table 5 presents the results of the estimation of relation (2) on the groups G3 and G4. By comparing the two groups G1 and G3 (Note 13), we observe that, except Romania, all countries of the group G1 are also in the group G3. Table 5 shows that the variable $S \mathrm{SO}_{90}$ divides our sample in two regimes characterizing the link between economic growth and the explanatory variables. We can note that in group G3 the variable $F T$ has a significant and negative coefficient which implies that free trade exerts a negative effect on economic growth for countries in this group (Note 14). But, in the same manner like in the preceding case, we can notice that the variable $S G$ has a significant coefficient which is positive in G3 and negative in G4. Therefore, for countries having an enrollment rate in 1990 bigger than 81.456, a reduction in the size of the government results in a negative effect on economic growth.

\section{Discussion of the results}

Our results show that the link between economic freedom and economic growth is not linear on the totality of the sample. By using threshold variables, our sample has been divided in two types of regimes characterizing the impact of economic freedom on growth. For countries with an initial GDP lower than 2080.46 and/or an enrollment rate in 1990 lower than 81.456, the reduction in the size of the government, the improvement of quality of the legal system and the effectiveness of the monetary policy are the components which exert positive effects on economic growth. For countries with an enrollment rate higher than 81.456, there is especially free trade and the absence of regulation on markets which exert positive effects on economic growth.

An important result of our work is that the reduction of the size of the government is effective only in countries with an enrollment rate in 1990 lower than 81.456. However, in the other countries, reducing the size of the government would result in a negative effect on growth. This leads us to put into perspectives the assumption of the necessity to reduce the size of the government in developing countries. Our results show that the problem of these countries remains that of the effectiveness of their economic policies. They show the importance of education, the importance of an effective legal system, the necessity of a consistent monetary policy and a good operation of markets in developing countries.

No one can deny the importance and the need for democracy, of the freedom of expression and any act aiming at improving the components of a descent life in the development process. Many policies are necessary for developing countries to meet the claims of their populations. However, an abrupt disengagement of the State in these countries would be a too premature and too risky stage.

Such as it is envisaged by its defenders, the concept of economic freedom does not pour in the interests of developing countries. On the contrary, it shows increasingly tended relations between the North and the South, and the number of countries which refuse this form of freedom does not cease increasing. For example, the brain drain that certain authors evoke shows well that in certain cases this freedom can lead to an impoverishment of poor countries. Nduru (2006), for example, insists on the effects of such a phenomenon on African countries. He notes the lack in medical staff in these countries and the departure of several medical professions towards developed countries. What France calls "selected immigration" proves that the relationship with the South is far from being those of mutual interests. Certain authors go further and consider that the assistances granted to poor countries were translated by many harmful effects. Rahnema (2003), for example, notes that what one continues to call assistance is only an expenditure intended to reinforce the generating structures of misery. On the other hand, the victims of the globalized world are never help and seek always to find alternatives conform to their needs.

Developing countries need a reorganization of their development policies. The liberalization of their markets requires policies that support the private sector. The solutions for the problems of unemployment, of professional insertion and of educational system effectiveness etc. are far from being spontaneous and automatic. The numerical fracture that has emerged these last years shows well that these economies are badly prepared to follow the world train of technology. The recent works on the productivity paradox and the role that must be accomplished by, at the same time, the production and the use of new communication and information technologies makes increasingly urgent the effective intervention of the State in the economy. The free trade, for example, does not make it possible to benefit automatically from technological trainings. In fact, some countries are very far from the world technological threshold and such a situation leaves them trapped in very low development levels (Stokke, 2005).

We live in a world where the speed of technological progress has attained one of its higher levels. Competitiveness of countries depends on their capacity of adaptation and continuation of progress. In such a world, the role of the State is increasingly significant. Lonely, the market is unable to establish, in other countries, the fascination for technology characterizing the Finnish people during the nineties. The market remains, in addition, impotent and nonselective in front of the waves of the very varied and sometimes strange ideas and cultures transferred by the current world of information. 


\section{Conclusion}

Independently of development levels, economic freedom is advanced by liberal economists as a priority action for development. Using an aggregate index, some studies show a positive correlation between economic freedom and growth. Our framework shows that the use of such an index can mask the true relationship between economic growth and the components of this index. Thus, our results show that the importance of the various components varies according to the development level of countries. In fact, our empirical study detects the presence of thresholds relating to the variables initial GDP per capita and initial enrollment rate in secondary school. So it rejects the assumption of a linear relation between economic growth and the explanatory variables. In addition, we show that reducing the size of the government is not always effective. Indeed, the coefficient attached to this variable is positive and significant in the whole of countries having an initial GDP and an enrollment rate that are relatively small, but this coefficient is negative and significant for the other countries. These results enable us to conclude that the positive effect of economic freedom proved by the majority of empirical studies on economic growth does not imply necessarily the need for a total disengagement of the government in the economy.

Such it is defined by its inventors; economic freedom neglects the specificity of developing countries and considers that liberalism would unconditionally offer to these countries the same opportunities as those of developed countries. In rich countries, the effective policies have been a prerequisite for a progressive liberalization of their economies. In developing countries, to be entitled to an effective intervention of the government should constitute the first component of economic freedom.

\section{References}

Barro, R. (1991). Economic growth in a cross section of countries, The Quarterly journal of Economics, $106 \quad \mathrm{~N}^{\circ} .2$, 407-443, doi:10.2307/2937943, http://dx.doi.org/10.2307/2937943.

Bengtsson, M., N. Berggren and H. Jordahl (2005) Trust and growth in the 1990s - A robust analysis, UPPSALA Universitet, Working Paper 2005 :1.

Bengtsson, M. and H. Jordahl (2005). Does free trade really reduce growth? Further testing using the economic freedom index, Public Choice, 122, 99-114.

Boockmann, B. and Drehel, A. (2001). The contribution of the IMF and the World Bank to economic freedom, Center of European Economic Research, Discussion Paper Nº.02-18.

Carlsson, F. and S. Lundström (2002) Economic freedom and growth : Decomposing the effects, Public Choice, 112, 335-344.

Chen, S-T and C-C. Lee. (2005). Government size and economic growth in Taiwan: A threshold regression approach, Journal of Policy Modeling, 27, 1051-1066, doi:10.1016/j.jpolmod.2005.06.006, http://dx.doi.org/10.1016/j.jpolmod.2005.06.006.

Chong, A. and C. Calderon. (2000). Causality and feedback between institutional measures and economic growth, Economics and Politics, 12, 69-81, doi:10.1111/1468-0343.00069, http://dx.doi.org/10.1111/1468-0343.00069.

Cole, J. H. (2003). The contribution of economic freedom to world economic growth, 1980-99, Cato Journal, 23, 189-198.

Dawson J. W. (2003). Causality in the freedom-growth relationship, European Journal of Political Economy, 19, 479-495, doi:10.1016/S0176-2680(03)00009-0, http://dx.doi.org/10.1016/S0176-2680(03)00009-0 .

De Soysa, I. and E. Neumayer. (2004), False Prophet, or Genuine Savior? Assessing the Effects of Economic Openness on Sustainable Development, 1980-1999, SSRN working paper, doi:10.2139/ssrn.586464, http://dx.doi.org/10.2139/ssrn.586464

Durlauf, S. and P. A. Johnson. (1995). Multiple regimes and cross-country growth behavior, Journal of Applied Econometrics, 10, 365-384, doi:10.1002/jae.3950100404, http://dx.doi.org/10.1002/jae.3950100404.

Esposto, A. and P. A. Zaleski. (1999). Economic freedom and the quality of life: an empirical analysis. Constitutional Political Economy. 10: 185-197.

Gwartney, J., R. Lawson and E. Gartzke. (2005). Economic Freedom of the World - 2005 annual report, The Fraser Institute.

Gwartney, J.D., G. H. Randall and R. A. Lawson. (2004). Economic freedom, institutional quality, and cross-country differences in income and growth, Cato Journal, 24, 205-233. 
Hall, R. E. and C. I. Jones. (1996). Why do some countries produce so much more output per worker than others? The Quarterly Journal of Economics, 114, 83-116, doi:10.2139/ssrn.3595, http://dx.doi.org/10.2139/ssrn.3595.

Hansen, B. E. (1996). Inference when a nuisance parameter is not identified under the null hypothesis, Econometrica, 64, 413-430, doi:10.2307/2171789, http://dx.doi.org/10.2307/2171789.

Hansen, B. E. (2000). Sample splitting and threshold estimation, Econometrica, 68, 575-603, doi:10.1111/1468-0262.00124, http://dx.doi.org/10.1111/1468-0262.00124.

Heckelman, J. C. and M. D. Stroup. (2000). Which economic freedoms contribute to growth? KYKLOS, 53, 527-544, doi:10.1111/1467-6435.00194, http://dx.doi.org/10.1111/1467-6435.00194.

Leamer, E. E. (1985). Sensitivity analyses would help, The American Economic Review, 75, 308-313.

Levine, R. and D. Renelt. (1992) .A sensitivity analysis of cross-country growth regressions, The American Economic Review, 82, 942-963.

Rousseeuw, P. J. (1984). Least median of squares regression, Journal of the American Statistical Association, 79, 871-880, doi:10.2307/2288718, http://dx.doi.org/10.2307/2288718.

Rousseeuw, P. J. and C. van Zomeren. (1990). Unmasking multivariate outliers and leverage points, Journal of the American Statistical Association, 85, 633-639, doi:10.2307/2289995, http://dx.doi.org/10.2307/2289995.

Sala-I-Martin, X. (1997). I just run two million regressions, The American Economic Review, 87, 178-183.

Schaefer, B D. (2003). Economic freedom: the path to African prosperity, Heritage Lectures, N778, January 15.

Stine, R. A. (1995). Graphical interpretation of variance inflation factors, The American Statistician, 49, 53-56, doi:10.2307/2684812, http://dx.doi.org/10.2307/2684812.

Stroup, R. L. (2003). Economic freedom and environmental quality, Proceedings, Federal Reserve Bank of Dallas, 73-90.

Sturm, J-E and J. de Haan. (2005). Determinants of long-term growth: new results applying robust estimation and extreme bounds, Empirical Economics, 30, 3, 597-617, doi:10.1007/s00181-005-0252-x, http://dx.doi.org/10.1007/s00181-005-0252-x,

Temple, J. (2000). The new growth evidence, Journal of Economic Literature, 37, 112-156, doi:10.1257/jel.37.1.112, http://dx.doi.org/10.1257/jel.37.1.112.

Temple, J. (2000). Growth regressions and what the textbooks don't tell you, Bulletin of Economic Research, 52.3, 181-205, doi:10.2139/ssrn.167332, http://dx.doi.org/10.2139/ssrn.167332.

Acknowledgment: We thank the Professor Christian Bidard for his comments and suggestions. Obviousle, all remaining errors and shortcomings are ours.

\section{Notes}

Note 1. Levine and Renelt, 1992 use the EBA (Extreme Bounds Analysis) method, due to Leamer, 1985 which consists in studying the sensitivity of the coefficients of studied variables to modifications in the specification of the estimated model.

Note 2. Indeed, using a more flexible version of the EBA, the author notes (p.182): “ My claim in this paper is that, if one is interested in knowing the coefficient of a particular variable in a growth regression, the picture emerging from the empirical growth literature is not the pessimistic "nothing is robust" obtained with the extreme bound analysis. Instead, a substantial number of variables can be found to be strongly related to growth."

Note 3. In the majority of empirical works, the variable SCO is regarded as a proxy for human capital. Other variables, such as the enrollnment ratio in the primary school and the literacy rate, can also be used. Barro (1991) notes that the calculation of the literacy rate suffers from several problems especially in developing countries. In addition, Levine and Renelt (1992) note that many countries already reached the maximum level of the literacy rate and the ratio of primary school. Thus, these variables would be unable to express the differences in the human capital between countries. Lastly, in their estimates, Green et al. (2002) use several indicators of human capital and note that the results are always the same.

Note 4. We have $G D P G=\left(\log \left(G D P_{2003}-G D P_{1972}\right) \times \frac{100}{31}\right)$

Note 5. http://pwt.econ.upenn.edu/

Note 6.The data are downloadable at: http://www.freetheworld.org/download.html. 
Note 7. The list of countries is given in appendix A.

Note 8. Compared to other standard procedures (as the Mahalanobis distance, for example), this method has the capacity to treat models with more than one explanatory variable. In the same way, this method can detect the aberrant values at the same time in the explained variables and the explanatory variables (Rousseeuw, 1984; Rousseeuw and Zomeren, 1990).

Note 9. The residuals relating to these countries are 3.8677 for China, -3.2846 for the Democratic Republic of Congo and -3.2519 for Zambia. In our case, the LTS method consists in minimizing the sum of the 79 smallest residuals. For more details on the method, see Rousseeuw, 1984; Rousseeuw and Zomeren, 1990; Bengtsson and al., 2005, Sturm and de Haan, 2005.

Note 10. The residual of the estimation by LTS relating to this country is equal to 3.1764.

Note 11. For an application of this test to time series, see for example Ben Salem and Perraudin, 2001 and Chen and Lee, 2005.

Note 12. The appendix B presents the whole of the groups of countries determined by the test of rupture. We have tried to test the presence of a threshold of second level, but for all the groups, the assumption of homogeneity of the coefficients is accepted. P-values for the variable $G D P_{72}$ relating to the groups G1, G2, G3 and G4 are respectively $0.267,0.527,0.351,0.673$. For the variable $S C O_{90}$, they are equal to $0.187,0.565,0.332$ and 0.698 , respectively.

Note 13. See appendix B.

Note 14. This result agrees with that of Carlsson and Lundström, 2002 who find a negative effect of free trade on economic growth, but this result is criticized by Berggren and Jordahl, 2005.

Table 1. Estimation results for the aggregate index (regression (1)

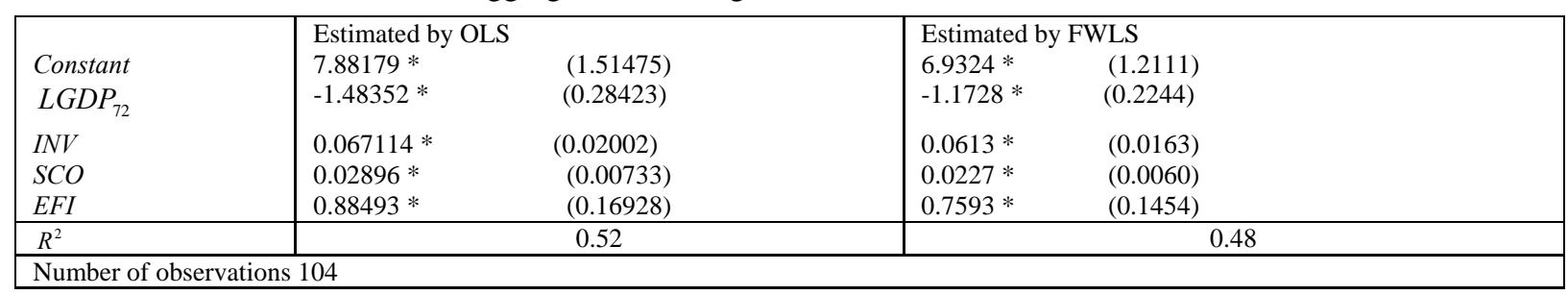

* significantly different from zero at $1 \%$ significance level, ** significantly different from zero at $5 \%$ significance level

The values in parentheses represent the standard errors corrected of heteroscedasticity by White 1980 method.

Table 2. Estimation results for the decomposed index (regression (2))

\begin{tabular}{|c|c|c|c|c|c|}
\hline \multirow[b]{2}{*}{ Constant } & \multicolumn{2}{|c|}{ Estimated by OLS } & \multicolumn{3}{|c|}{ Estimated by FWLS } \\
\hline & $7.00534 *$ & $(1.23520)$ & $6.5642 *$ & (1.1661) & \\
\hline$L G D P_{72}$ & $-1.18053 *$ & $(0.23668) \quad[4.43256]$ & $-1.0701 *$ & $(0.2176)$ & [4.56583] \\
\hline$I N V$ & $0.07156 *$ & $(0.01929) \quad[2.53923]$ & $0.0653 *$ & $(0.0186)$ & [2.56553] \\
\hline$S C O$ & $0.02287 *$ & $(0.00708) \quad[5.29028]$ & $0.0230 *$ & $(0.0070)$ & {$[5.28890]$} \\
\hline$S G$ & 0.18230 & $(0.11007) \quad$ [1.91049] & $0.2255 * *$ & $(0.1028)$ & [1.94844] \\
\hline$L S$ & 0.20111 & $(0.13312) \quad[4.55584]$ & 0.2001 & $(0.1298)$ & [4.54561] \\
\hline$S M$ & $0.18589 * *$ & $(0.07653) \quad[2.07468]$ & $0.1992 * *$ & $(0.0760)$ & {$[2.08400]$} \\
\hline$F T$ & -0.08469 & $(0.12724) \quad[3.14750]$ & -0.1061 & $(0.1282)$ & [3.14207] \\
\hline$R E G$ & 0.26107 & $(0.18051)$ & 0.1773 & $(0.1698)$ & [2.94086] \\
\hline$R^{2}$ & \multicolumn{2}{|r|}{0.49} & \multicolumn{3}{|c|}{0.49} \\
\hline
\end{tabular}

* significantly different from zero at $1 \%$ significance level, ** significantly different from zero at $5 \%$ significance level The values in parentheses represent the standard errors corrected of heteroscedasticity by the White method. The values between hooks represent the variance inflation. 
Table 3. Test of rupture for the relation (2)

\begin{tabular}{|c|c|c|}
\hline & Value of the LM test & Bootstrap $P$-value \\
\hline$G D P_{72}$ & 33.352457 & 0.000 \\
\hline$S C O_{90}$ & 30.717982 & 0.000 \\
\hline
\end{tabular}

Table 4. Estimation results for the decomposed index for the groups G1 and G2

\begin{tabular}{|c|c|c|c|c|}
\hline & \multicolumn{2}{|c|}{ Group G1 ( $\left.G D P_{72} 2080.46\right)$} & \multicolumn{2}{|c|}{ Group G2 ( $\left.G D P_{72}>2080.46\right)$} \\
\hline Constant & $4.905408 *$ & $(1.280899)$ & $19.268150 *$ & $(1.526964)$ \\
\hline$L G D P_{72}$ & $-1.256161 *$ & (0.266056) & $-2.173485 *$ & $(0.192461)$ \\
\hline$I N V$ & $0.075858 *$ & $(0.023933)$ & 0.025665 & $(0.016154)$ \\
\hline $\mathrm{SCO}$ & $0.034603 *$ & (0.007975) & $-0.014443 * *$ & $(0.005601)$ \\
\hline$S G$ & $0.301022 * *$ & $(0.124136)$ & $-0.211079 * *$ & $(0.070851)$ \\
\hline$L S$ & $0.736462 *$ & $(0.129282)$ & 0.004389 & $(0.142678)$ \\
\hline$S M$ & $0.252999 *$ & (0.074059) & 0.122379 & $(0.101573$ \\
\hline$F T$ & -0.284675 & (0.159627) & $0.282353 * *$ & (0.077299) \\
\hline$R E G$ & 0.197125 & (0.166293) & $0.555123 *$ & (0.122099) \\
\hline$R^{2}$ & & 0.64 & \multicolumn{2}{|c|}{0.83} \\
\hline Number of observations & & 66 & \multicolumn{2}{|c|}{34} \\
\hline
\end{tabular}

* significantly different from zero at $1 \%$ significance level, ** significantly different from zero at $5 \%$ significance level.

The values in parentheses represent the standard errors corrected of heteroscedasticity by the White method.

Table5. Estimation results for the decomposed index for the groups G3 and G4

\begin{tabular}{|c|c|c|}
\hline & Group G3 ( $\left.S C O_{90} \leq 81.456\right)$ & Group G4 ( $\left.\mathrm{SCO}_{90}>81.456\right)$ \\
\hline Constant & $4.696338 *$ & $21.480645 *$ \\
\hline$L G D P_{72}$ & $-1.048613 * \quad(0.207635)$ & $-2.516273 *$ \\
\hline$I N V$ & $0.059790 * *$ & $0.049544 * *$ \\
\hline$S C O$ & $0.028784 *$ & $-0.017096 * *$ \\
\hline$S G$ & $0.235108 * *$ & $-0.228158 * *$ \\
\hline$L S$ & $0.555754 *$ & $(0.213680)$ \\
\hline$S M$ & $0.280231 *$ & $(0.114586)$ \\
\hline$F T$ & $-0.297426 * *$ & $0.328616 * *$ \\
\hline$R E G$ & 0.265341 & $0.765233 *$ \\
\hline$R^{2}$ & 0.66 & 0.77 \\
\hline Number of observations & 73 & 27 \\
\hline
\end{tabular}

* significantly different from zero at $1 \%$ significance level, ** significantly different from zero at $5 \%$ significance level.

The values in parentheses represent the standard errors corrected of heteroscedasticity by the White method. 


\section{Appendix A}

\section{List of countries of the initial sample}

\begin{tabular}{|c|c|c|}
\hline Algeria & Guatemala & Panama \\
\hline Argentina & Guinea-Bissau & Papua New Guinea \\
\hline Australia & Honduras & Paraguay \\
\hline Austria & Hong Kong & Peru \\
\hline Bahrain & Hungary & Plain Arab Emirates \\
\hline Bangladesh & Iceland & Poland \\
\hline Barbados & India & Portugal \\
\hline Belgium & Indonesia & Republic of Congo \\
\hline Belize & Iran & Romania \\
\hline Benin & Ireland & Senegal \\
\hline Bolivia & Israel & Sierra Leone \\
\hline Botswana & Italy & Singapore \\
\hline Brazil & Ivory Coast & South Africa \\
\hline Burundi & Jamaica & Spain \\
\hline Cameroon & Japan & Sri Lanka \\
\hline Canada & Jordan & Sweden \\
\hline Central African Rep & Kenia & Switzerland \\
\hline Chad & Kuwait & Syria \\
\hline Chile & Luxemburg & Tanzania \\
\hline China & Madagaskar & Thailand \\
\hline Colombia & Malawi & The Bahamas \\
\hline Costa Rica & Malaysia & The Netherlands \\
\hline Cyprus & Mali & The Philippines \\
\hline Dem Rep of Congo & Malta & The United States \\
\hline Denmark & Maurice & Togo \\
\hline Dominican Republic & Mexico & Trinidad \&Tobago \\
\hline Ecuador & Morocco & Tunisia \\
\hline Egypt & Nepal & Turkey \\
\hline El Salvador & New Zealand & Uganda \\
\hline Fiji & Nicaragua & United Kingdom \\
\hline Finland & Niger & Uruguay \\
\hline France & Nigeria & Venezuela \\
\hline Germany & Norway & Zambia \\
\hline Ghana & Oman & Zimbabwe \\
\hline Greece & Pakistan & \\
\hline
\end{tabular}




\section{Appendix B}

\begin{tabular}{|c|c|c|c|c|c|}
\hline \multicolumn{2}{|c|}{$G D P_{72} \leq 2080.46$} & $\begin{array}{c}\text { G2 } \\
G D P_{72}>2080.46\end{array}$ & \multicolumn{2}{|c|}{$\begin{array}{c}\text { G3 } \\
S C O_{90} \leq 81.456\end{array}$} & $\begin{array}{c}\text { G4 } \\
S C O_{90}>81.456\end{array}$ \\
\hline Malawi & Romania & Hungary & Tanzania & Indonesia & Australia \\
\hline Tanzania & Malaysia & Singapore & Burundi & India & Italy \\
\hline Guinea-Bissau & Bolivia & Trinidad \&Tobago & Niger & Jordan & Malta \\
\hline Mali & Paraguay & Portugal & Mali & Tunisia & Israel \\
\hline Burundi & Turkey & Hong Kong & Malawi & Oman & United Kingdom \\
\hline Nepal & Dominican Rep & Bahrain & Chad & Turkey & Barbados \\
\hline Chad & Zimbabwe & Ireland & Guinea-Bissau & Zimbabwe & New Zealand \\
\hline Indonesia & Ecuador & Greece & Central African Rep & Colombia & Sweden \\
\hline Niger & Guatemala & Argentina & Benin & Syria & Romania \\
\hline Benin & Algeria & Spain & Papua New Guinea & Maurice & The Bahamas \\
\hline Cent African Rep & Fiji & United Arab Emirates & Uganda & Rep of Congo & United States \\
\hline Uganda & Colombia & Barbados & Senegal & Mexico & Greece \\
\hline Nigeria & Tunisia & Italy & Sierra Leone & Iran & Japan \\
\hline India & Belize & Israel & Madagascar & Ecuador & Germany \\
\hline Sierra Leone & Jordan & Finland & Bangladesh & Fiji & France \\
\hline Rep of Congo & El Salvador & Japan & Ivory Coast & Malaysia & Switzerland \\
\hline Togo & Malta & Iceland & Pakistan & Algeria & Island \\
\hline Pakistan & Poland & United Kingdom & Guatemala & Panama & Bahrain \\
\hline Kenya & Maurice & Belgium & Togo & Jamaica & Ireland \\
\hline Bangladesh & Jamaica & Austria & Kenya & U.A.E & Canada \\
\hline Madagascar & Peru & Germany & Nigeria & Peru & Belgium \\
\hline Syria & Panama & Norway & El Salvador & Portugal & Norway \\
\hline Sri Lanka & Brazil & France & Cameroon & Singapore & Austria \\
\hline Senegal & Mexico & Canada & Thailand & Argentina & Spain \\
\hline Ghana & Costa Rica & New Zealand & Paraguay & Cyprus & Denmark \\
\hline Cameroon & Oman & The Bahamas & Nepal & The Philippines & Finland \\
\hline Honduras & Venezuela & Australia & Honduras & Chile & Netherlands \\
\hline Thailand & Nicaragua & The Netherlands & Venezuela & Sri Lanka & \\
\hline Morocco & Iran & Sweden & Morocco & South Africa & \\
\hline Ivory Coast & Uruguay & Denmark & Ghana & Luxembourg & \\
\hline Papua New Guinea & South Africa & The United States & Bolivia & Egypt & \\
\hline Egypt & Cyprus & Luxembourg & Brazil & Hungary & \\
\hline The Philippines & Chile & Switzerland & Dominican Rep & Hong Kong & \\
\hline & & Kuweit & Nicaragua & Trinidad & \\
\hline & & & Belize & \&Tobago & \\
\hline & & & Costa Rica & Uruguay & \\
\hline & & & Kuweit & Poland & \\
\hline
\end{tabular}

